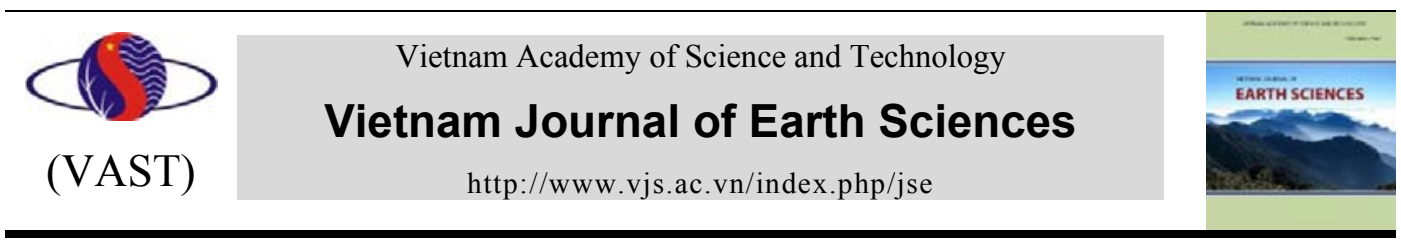

\title{
Application of directional derivative method to determine boundary of magnetic sources by total magnetic anomalies
}

\author{
Nguyen Thi Thu Hang1, Do Duc Thanh*1, Le Huy Minh² \\ ${ }^{I}$ Hanoi University of Science (VNU) \\ ${ }^{2}$ Institute of Geophysics (VAST)
}

Received 27 May 2017. Accepted 01 September 2017

\begin{abstract}
This paper presents the Directional Derivative method to determine location and boundaries of the magnetic directional structure sources through a new function DG (Directional Gradient - DG). Algorithm and computer program are made a code by Matlab language to attempt to calculate on 3D models in the compare with Horizontal derivative method (HG). A new function DG also applied to determine the boundary of magnetic sources by the total magnetic anomalies of Tuan Giao region. The result shows that with the application of new function DG, the boundaries of magnetic sources are exactly defined although they have a directional structure and small horizontal size. Moreover, because it does not depend on directions of magnetization, so in the computation, the transformation of the magnetic field to the pole can ignore, thus, reduce transient error. Alternatively, with the application of new function DG, the interferences in case the sources distributed close together are overcome. This usefulness affirms the possibility of application of the this method in the analysis and interpretation of magnetic data in Vietnam.
\end{abstract}

Keywords: Magnetic anomaly; Magnetized prism; Horizontal Gradient; Directional Gradient; Tuan Giao.

(C)2017 Vietnam Academy of Science and Technology

\section{Introduction}

In magnetic exploration, the quantitative interpretation or the solution of the inverse problem to determine the location, shape, depth, magnetization of geological objects causing observed anomalies always plays an important role. In recent years, in Vietnam, many modern methods for determining the location of geological sources based on total magnetic anomalies $\Delta \mathrm{Ta}$ have been studied and applied such as the method of determining maximum horizontal gradient vector field

"Corresponding author, Email: doducthanh1956@gmail.com
(Le Huy Minh et al., 2001; Le Huy Minh et al., 2002), the method of calculating vertical derivative and its maximum horizontal gradient vector (Vo Thanh Son et al., 2005), the method of analytic signals (Vo Thanh Son et al., 2005; Vo Thanh Son et al., 2007). The research results show that besides the advantages, these methods have many limitations in overcoming the problem of interference in case the actual conditions are complex and the differentiation of the sources is not clear. On the other hand, the studies also show that in most methods, the accuracy of analytical results depends on the isometry and magnetization inclination of the anomaly- 
generating object. It makes the analysis, processing, and interpretation of magnetic data by these methods more complicated because they must be combined with the calculation programs for reduction to the pole. In addition, this intermediate step will result in significant errors in the analysis, especially in case the study area is located in a low-latitude region. Based on this fact, in this article, we have studied and proposed the application of directional gradient (DG) in combination with the determination of the maximum of $\mathrm{DG}$ function $\left(\left|\mathrm{DG}_{\max }\right|\right)$ according to the algorithm of Blakely and Simpson (1986) in order to define the boundary of banded geological objects which extend in one direction and have different magnetic properties in the Earth's crust. The method is implemented by a program written in the Matlab language which has been tested on 3D models in comparison with the method of calculating maximum horizontal gradient vector field (HG). The DG function is also used to interpret the aeromagnetic anomaly map in Tuan Giao area, thereby evaluating the effectiveness of the presented method.

\section{Methodology}

\subsection{Horizontal derivative}

Suppose $f(x, y)$ is a smoothly-varying scalar quantity measured on a horizontal plane. The horizontal derivatives of $\mathrm{f}(\mathrm{x}, \mathrm{y})$ are easily evaluated by using the finite difference method and the measured values of $\mathrm{f}(\mathrm{x}, \mathrm{y})$. If $\mathrm{f}_{\mathrm{ij}}$, with $i=1,2, \ldots, j=1,2, \ldots$ are the measured values of $f(x, y)$ on a regular grid with the steps $\Delta x$ and $\Delta y$, the horizontal derivatives of $\mathrm{f}(\mathrm{x}, \mathrm{y})$ at the point $(\mathrm{i}, \mathrm{j})$ is approximated by:

$$
\begin{gathered}
\frac{d f(x, y)}{d x} \approx \frac{f_{i+1, j}-f_{i-1, j}}{2 \Delta x} \\
\frac{d f(x, y)}{d y} \approx \frac{f_{i, j+1}-f_{1, j-1}}{2 \Delta y}
\end{gathered}
$$

The horizontal derivatives are also easily implemented in the frequency domain. Ac- cording to difference theory, the Fourier transform of $\mathrm{n}^{\text {th }}$-order horizontal derivatives of $\mathrm{f}(\mathrm{x}$, y) is defined as follows:

$$
\begin{aligned}
& F\left[\frac{d^{n} f}{d x^{n}}\right]=\left(i k_{x}\right)^{n} F[f] \\
& F\left[\frac{d^{n} f}{d y^{n}}\right]=\left(i k_{y}\right)^{n} F[f]
\end{aligned}
$$

Thus, in the frequency domain, the calculation of horizontal derivative of a potential field measured on a horizontal plane can be defined as a three-step filtering operator: Fourier transform of potential field, multiplication by the corresponding filters $\left(i k_{x}\right)^{n}$ and $\left(i k_{y}\right)^{n}$, and then inverse Fourier transformation of obtained products.

\subsection{Directional derivative}

The directional derivative denoted as $D_{\hat{s}} f$ is the rate of change of $\mathrm{f}(\mathrm{x}, \mathrm{y})$ at the point $\left(\mathrm{x}_{0}, \mathrm{y}_{0}\right)$ in the direction of unit vector $\hat{s}$. It is a vector form of the usual derivative and can be defined as:

$D_{\hat{s}} f(x, y)=\vec{\nabla}_{f} \cdot \frac{\vec{s}}{|\vec{s}|}=\lim _{h \rightarrow 0} \frac{f(x+a h, y+b h)-f(x, y)}{h}$

Where $\vec{\nabla}$ is the nabla operator and $\hat{s}$ is the unit vector in the Cartesian coordinate system. In the horizontal plane, with $\hat{s}=\left(s_{x}, s_{y}\right)$,

we have: $|\hat{s}|=\sqrt{s_{x}^{2}+s_{y}^{2}}=1$

thus

$$
D_{\hat{s}} f(x, y)=\frac{\partial f(x, y)}{\partial x} s_{x}+\frac{\partial f(x, y)}{\partial y} s_{y}
$$

If $\hat{s}$ makes an angle $\alpha$ with the positive side of the Ox axis, then we have $\hat{s}=(\cos \alpha, \sin \alpha)$. Therefore, the derivative of $\mathrm{f}(\mathrm{x}, \mathrm{y})$ in the direction of the vector $\hat{s}$ is:

$$
D_{\hat{s}} f(x, y)=\frac{\partial f(x, y)}{\partial x} \cos \alpha+\frac{\partial f(x, y)}{\partial y} \sin \alpha
$$

If $\mathrm{f}(\mathrm{x}, \mathrm{y})$ is the function of total magnetic anomalies $\Delta \mathrm{T}(\mathrm{x}, \mathrm{y})$ caused by an object whose extending direction makes an angle $\alpha$ with the 
Vietnam Journal of Earth Sciences, 39(4), 360-375

Oy axis, then according to the above definition, at the point $\mathrm{M}(\mathrm{x}, \mathrm{y})$ on the horizontal plane, the derivative of $\Delta \mathrm{T}(\mathrm{x}, \mathrm{y})$ in the direction of the vector $\hat{s}$, which is perpendicular to the structural direction of the source, is defined as follows:

$$
D_{\hat{s}} \Delta T=\frac{\partial \Delta T}{\partial x} \cos \alpha+\frac{\partial \Delta T}{\partial y} \sin \alpha
$$

In numerical calculation, the values of the magnetic field are observed on a regular grid, the DG function representing derivative values on the horizontal plane at the point $(i, j)$ in the direction $\hat{s}$ (Figure 1) is defined by the formula:

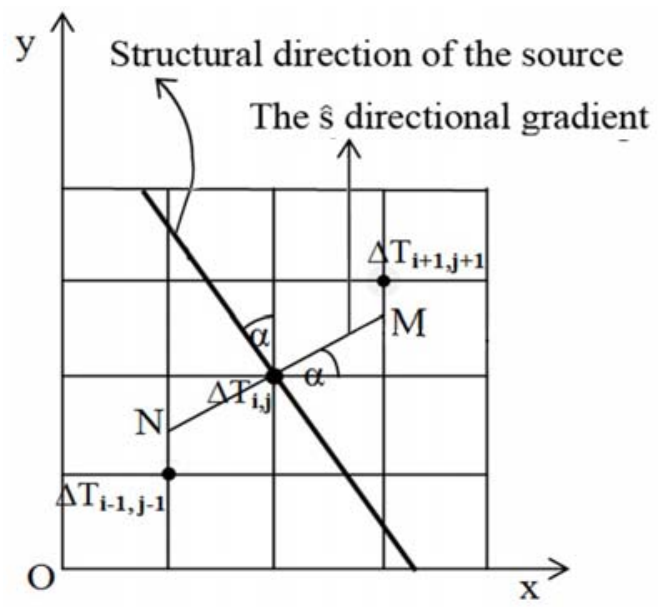

Figure 1. The $\hat{s}$ directional gradient of total magnetic anomaly field at observation point $(\mathrm{i}, \mathrm{j})$

$D G=D_{\hat{s}} \Delta T(i, j) \approx \frac{\Delta T_{M}-\Delta T_{N}}{d}$ with $\mathrm{d}=|\mathrm{MN}|$

In case $\mathrm{M}$ and $\mathrm{N}$ do not coincide with the grid cells, we use the interpolation method to find the values $\Delta T_{M}$ and $\Delta T_{N}$. In order to find $\Delta \mathrm{T}_{\mathrm{M}}$, we perform the following steps:

Using the algorithm to select the grid cell closest to $\mathrm{M}$ as the origin. In this case, it is the point $(\mathrm{i}+1, \mathrm{j}+1)$.

The value of $\Delta T_{M}$ is determined by the method of least squares. According to this method, the magnetic field around the origin, namely the point $(\mathrm{i}+1, \mathrm{j}+1)$, within the radius $\mathrm{R}$, containing $\mathrm{N}$ observed values is represent- ed by a quadratic polynomial. Then, the magnetic field interpolated at the point $M$ is defined by:

$\Delta T_{M}(\mathrm{x}, \mathrm{y})=\mathrm{a}\left(\mathrm{x}-\mathrm{x}_{0}\right)^{2}+\mathrm{b}\left(\mathrm{x}-\mathrm{x}_{0}\right)\left(\mathrm{y}-\mathrm{y}_{0}\right)+$ $\mathrm{c}\left(\mathrm{y}-\mathrm{y}_{0}\right)^{2}+\mathrm{d}\left(\mathrm{x}-\mathrm{x}_{0}\right)+\mathrm{e}\left(\mathrm{y}-\mathrm{y}_{0}\right)+\mathrm{f}$

where $\left(\mathrm{x}_{0}, \mathrm{y}_{0}\right)$ are the coordinates of the point $(i+1, j+1)$ selected as the origin, $(x, y)$ are the coordinates of $\mathrm{M}$, and the coefficients of expansion $a, b, c, d, e, f$ are selected in such a way that:

$$
\sum_{k=1}^{N} P_{k}\left[\Delta T_{q s}(k)-\Delta T(k)\right]^{2}=\min
$$

where $\Delta T_{q s}(k)$ is the value of magnetic field observed at the $\mathrm{k}^{\text {th }}$ point among $\mathrm{N}$ observation points within the radius R. $P_{k}$ is the weighting function, defined as follows:

$$
P_{k}=\left(\frac{R-d_{k}^{2}}{d_{k}^{2}-\eta}\right)^{\gamma}
$$

where $d_{k}$ is the distance from the origin to the $\mathrm{k}^{\text {th }}$ point; $\eta$ and $\gamma$ are the coefficients.

The determination of the value of magnetic field $\Delta \mathrm{T}_{\mathrm{N}}$ at the point $\mathrm{N}$ is similarly carried out. In this case, the point selected as the origin for the interpolation is the point (i-1, $\mathrm{j}$ 1) which is closest to N. After determining the DG function at all observation points, the positions of its maximum values $\left|\mathrm{DG}_{\max }\right|$ are also identified by the algorithm introduced by Blakely and Simpson (1986).

\subsection{Determination of the maximum values $\left|D G_{\max }\right|$}

According to Blakely and Simpson (1986), the maxima of $|\mathrm{DG}|$ function $\left(\left|\mathrm{DG}_{\max }\right|\right)$ are calculated by comparing the value $|\mathrm{DG}(\mathrm{x}, \mathrm{y})|$ at each point of the grid with 8 surrounding points. Thus, at each grid cell $(i, j)$, it is necessary to verify the following double inequalities:

$|\mathrm{DG}(\mathrm{i}-1, \mathrm{j})|<|\mathrm{DG}(\mathrm{i}, \mathrm{j})|>|\mathrm{DG}(\mathrm{i}+1, \mathrm{j})|$

$|\mathrm{DG}(\mathrm{i}, \mathrm{j}-1)|<|\mathrm{DG}(\mathrm{i}, \mathrm{j})|>|\mathrm{DG}(\mathrm{i}, \mathrm{j}+1)|$

$|\mathrm{DG}(\mathrm{i}+1, \mathrm{j}-1)|<|\mathrm{DG}(\mathrm{i}, \mathrm{j})|>|\mathrm{DG}(\mathrm{i}-1, \mathrm{j}+1)|$

$|\mathrm{DG}(\mathrm{i}-1, \mathrm{j}-1)|<|\mathrm{DG}(\mathrm{i}, \mathrm{j})|>|\mathrm{DG}(\mathrm{i}+1, \mathrm{j}+1)|$ 
Nguyen Thi Thu Hang, et al./Vietnam Journal of Earth Sciences 39 (2017)

When a double inequality is satisfied, the counter $\mathrm{N}$ will increase by one. Thus, at each grid cell, $\mathrm{N}$ can get the values from 0 to 4 . The counter $\mathrm{N}$ is the measure of the quality of the maximum or the significance level of the maximum. For each satisfied double inequality, the maximum value and position of $\mathrm{DG}(\mathrm{x}$, y) are interpolated by approximating $\mid \mathrm{DG}(\mathrm{x}$, y)| by a parabola through 3 corresponding points. For example:

If we have

$|\mathrm{DG}(\mathrm{i}-1, \mathrm{j})|<|\mathrm{DG}(\mathrm{i}, \mathrm{j})|>\mid \mathrm{DG}(\mathrm{i}+1, \mathrm{j})$

then the maximum position of $|\mathrm{DG}|$ function compared to the position of DG(i,j) is identified by:

$$
x_{\max }=-\frac{b d}{2 a}
$$

where:

$a=\frac{1}{2}(|\mathrm{DG}(\mathrm{i}-1, \mathrm{j})|-2|\mathrm{DG}(\mathrm{i}, \mathrm{j})|+|\mathrm{DG}(\mathrm{i}+1, \mathrm{j})|)(14$

$b=\frac{1}{2}(|\mathrm{DG}(\mathrm{i}+1, \mathrm{j})|-|\mathrm{DG}(\mathrm{i}-1, \mathrm{j})|)$

$d$ is the distance between the grid cells.

The value of $|\mathrm{DG}(\mathrm{i}, \mathrm{j})|$ at the point $\mathrm{x}_{\max }$ is given by (Figure 2):

$\left|\mathrm{DG}_{\max }\right|=\mathrm{ax}_{\text {max }}^{2}+\mathrm{bx}_{\text {max }}+|\mathrm{DG}(\mathrm{i}, \mathrm{j})|$

If more than one double inequality is satisfied, the largest $\left|\mathrm{DG}_{\max }\right|$ and its corresponding position $\mathrm{x}_{\max }$ will be selected.

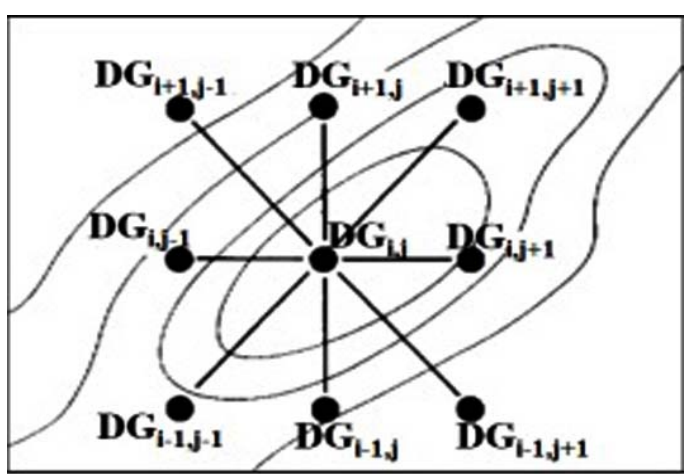

Figure 2. Determination of maximum values of $|\mathrm{DG}|$ function (modified from Blakely and Simpson, 1986)

\section{Results}

\subsection{Experimental results on the model}

Based on the method of calculating horizontal gradient vector field (HG) and the method of calculating directional gradient (DG) of total magnetic anomalies, we have developed a program to compute these functions, then used the algorithm of Blakely and Simpson (1986) to identify the positions of their maxima $|\mathrm{HG}|_{\max }$ and $|\mathrm{DG}|_{\max }$ by the Matlab language in order to determine the boundary and position of anomaly-generating object on some models of magnetized object with the structure extending in one direction. In models, total magnetic anomalies caused by the objects are determined on the $\mathrm{xOy}$ plane with the origin $\mathrm{O}$ located on the observation plane, the Oy axis running towards the geographic North Pole, the Ox axis running eastwards, the $\mathrm{Oz}$ axis running vertically downwards. The observation grid parallel to the Ox and Oy axes has:

- The number of observation points according to the Ox axis: 316 points

- The number of observation points according to the Oy axis: 316 points

- Distance between observation points: $\Delta x=\Delta y=0.2 \mathrm{~km}$

By selecting the coordinate system as above, total magnetic anomalies of the magnetized object with the magnetization angle I in the shape of vertical prism are determined according to Bhaskara Rao and Ramesh Babu (1993). To evaluate the effectiveness of the directional gradient of total magnetic anomalies, in each model, we perform the following steps:

- Mixing noise of the Gaussian distribution (1\%) into the magnetic field $\Delta T(x, y)$ calculated from the model and considering it as an observation field.

- Calculating and comparing the results of determining object boundary according to the maximum positions of $\mathrm{HG}$ function $\left(|\mathrm{HG}|_{\max }\right)$ and DG function $\left(|\mathrm{DG}|_{\max }\right)$. 
Vietnam Journal of Earth Sciences, 39(4), 360-375

\subsubsection{Model of one magnetized prism}

In this model, the magnetic anomaly source is a vertical prism magnetized under an inclination $\mathrm{I}=25^{\circ}$. This model is established to evaluate the effectiveness of the method in determining boundaries of banded magnetized objects which have the narrow width and extend in one direction. In this case, the selected direction of the source is northwest - southeast. The parameters regarding coordinates, geometric dimensions and magnetization of the prism are presented in Table 1.

Table 1. Parameters of a magnetized prism

\begin{tabular}{|c|c|c|c|c|c|c|c|c|}
\hline Parameters & $\begin{array}{l}\text { Center coor- } \\
\text { dinate }(\mathrm{km})\end{array}$ & $\begin{array}{l}\text { Magnetic dec- } \\
\text { lination }\left({ }^{\circ}\right)\end{array}$ & $\begin{array}{l}\text { Magnetization } \\
(\mathrm{A} / \mathrm{m})\end{array}$ & $\begin{array}{c}\text { Edge } \\
\text { length } \\
(\mathrm{km})\end{array}$ & $\begin{array}{l}\text { Edge } \\
\text { width } \\
(\mathrm{km})\end{array}$ & $\begin{array}{c}\text { Depth to } \\
\text { the top } \\
(\mathrm{km})\end{array}$ & $\begin{array}{l}\text { Depth to } \\
\text { the bot- } \\
\text { tom (km) }\end{array}$ & $\begin{array}{l}\text { Magnetic in- } \\
\text { clination }\left({ }^{\circ}\right)\end{array}$ \\
\hline Value & $31.5 ; 31.5$ & 0 & 4 & 70 & 0.3 & 0.5 & 5.0 & 25 \\
\hline
\end{tabular}

To investigate the effect of magnetic inclination on the accuracy of the method, both $|H G|_{\text {max }}$ and $|D G|$ of the reduced-to-the-pole anomalies

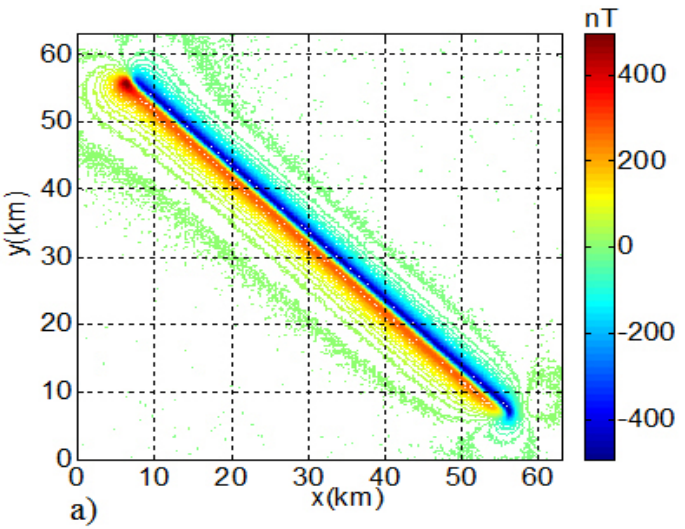

(Figure 3a) and of the not-reduced-to-the-pole anomalies (Figure 3b) are calculated. The calculation results are represented in Figure 4.

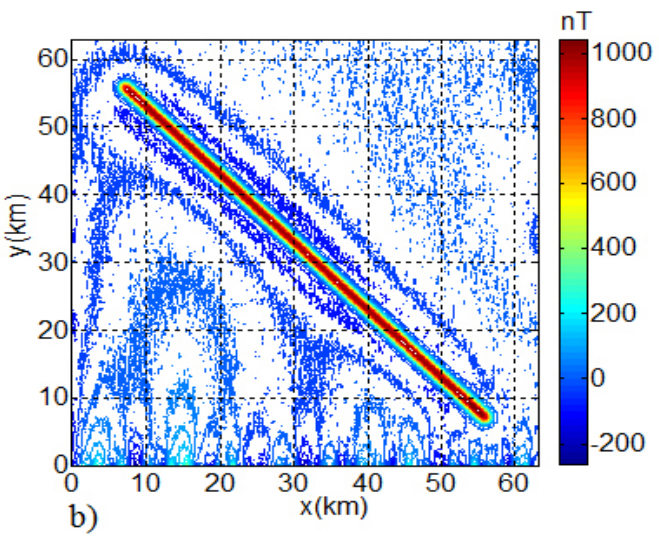

Figure 3. Anomalies with noise of $1 \%$ of a magnetized prism: a) Magnetic inclination $I=25^{\circ} ;$ b) Reduced to the pole

Remarks: Based on the calculation results on the model of one magnetized prism with the structure extending in one direction, the following remarks can be made in the correlation between the two methods of the horizontal gradient vector field ( $\mathrm{HG}$ ) and directional gradient (DG) to determine the boundary of the source:

- In the method of using the maximum values of $\mathrm{HG}$ function, if the anomalies are not reduced to the pole, the boundary of the object will not be sufficiently determined, the two boundaries in the extending direction of the object seem to be reduced to a straight line coinciding with the extending axis of the object (Figure 4a). It is only fully determined in case the anomalies are reduced to the pole before calculating HG (Figure 4b).

- According to the maximum values of $|\mathrm{DG}|$ function $\left(|\mathrm{DG}|_{\max }\right)$, the determination of the boundary of the source is completely independent of the magnetic inclination of the source; even in case the anomalies are not reduced to the pole, the boundary of the source is sharply and clearly represented (Figure 4c, d).

\subsubsection{Model of two parallel magnetized prisms}

This model is established to investigate the effectiveness of the method of using the |DG| function to determine magnetic boundaries in case of many magnetic anomaly 
Nguyen Thi Thu Hang, et al./Vietnam Journal of Earth Sciences 39 (2017)

sources in the study area. The magnetic anomaly sources include two vertical prisms magnetized under an inclination $\mathrm{I}=25^{\circ}$, their structural direction makes an angle of $45^{\circ}$
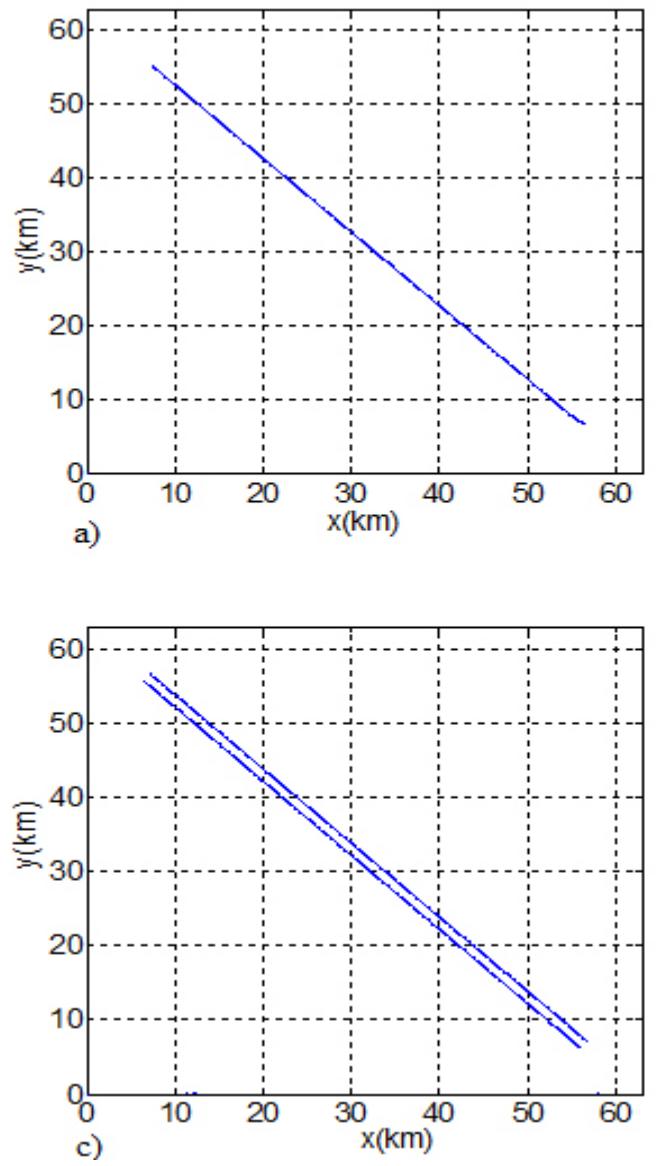

with the north. The parameters regarding coordinates, geometric dimensions and magnetization of the prisms are presented in Table 2.
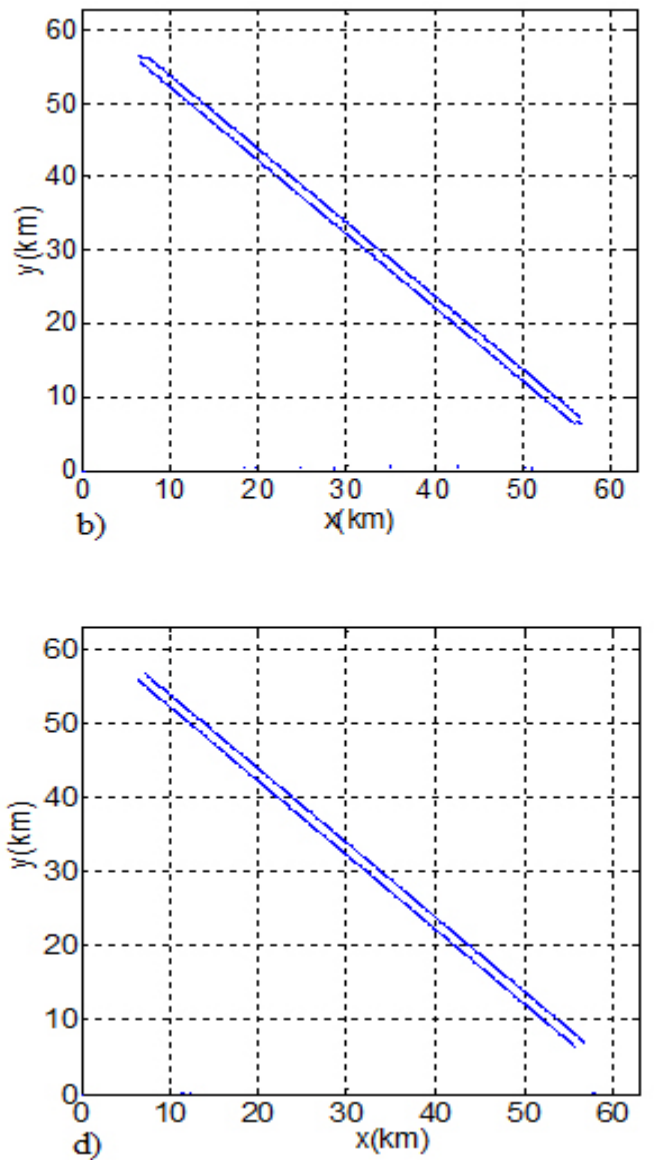

Figure 4. Determination of the boundary of a magnetized prism: a) Boundaries of object determined by $|\mathrm{HG}|_{\max }$ in case the anomalies are not reduced to the pole; b) Boundaries of object determined by $|\mathrm{HG}|_{\max }$ in case the anomalies are reduced to the pole; c) Boundaries of object determined by $|\mathrm{DG}|_{\max }$ in case the anomalies are not reduced to the pole; d) Boundaries of object determined by $|\mathrm{DG}|_{\max }$ in case the anomalies are reduced to the pole

Table 2. Parameters of two parallel magnetized prisms

\begin{tabular}{|c|c|c|c|c|c|c|c|c|}
\hline Parameters & $\begin{array}{c}\text { Center } \\
\text { coordinate } \\
(\mathrm{km})\end{array}$ & $\begin{array}{c}\text { Magnetic } \\
\text { declination } \\
\left({ }^{\circ}\right)\end{array}$ & $\begin{array}{l}\text { Magnetization } \\
(\mathrm{A} / \mathrm{m})\end{array}$ & $\begin{array}{l}\text { Edge } \\
\text { length } \\
(\mathrm{km})\end{array}$ & $\begin{array}{l}\text { Edge } \\
\text { width } \\
(\mathrm{km})\end{array}$ & $\begin{array}{c}\text { Depth to } \\
\text { the top } \\
(\mathrm{km})\end{array}$ & $\begin{array}{l}\text { Depth to the } \\
\text { bottom } \\
(\mathrm{km})\end{array}$ & $\begin{array}{c}\text { Magnetic } \\
\text { inclination } \\
\left({ }^{\circ}\right)\end{array}$ \\
\hline Prism1 & $29.0 ; 31.5$ & 0 & 4 & 70 & 0.3 & 0.5 & 5.0 & 25 \\
\hline Prism2 & $34.0 ; 31.5$ & 0 & 4 & 70 & 0.3 & 0.5 & 5.0 & 25 \\
\hline
\end{tabular}

Both the not-reduced-to-the-pole anomalies $\left(\mathrm{I}=25^{\circ}\right)$ and the reduced-to-the-pole anomalies $\left(\mathrm{I}=90^{\circ}\right)$ are represented in Figure 5a, b, respec- tively. In this case, as the structural direction of the anomaly-generating object makes an inclination of $-45^{\circ}$ with the Oy axis (counterclock- 
Vietnam Journal of Earth Sciences, 39(4), 360-375

wise), the selected gradient direction, which is perpendicular to the strike line of the object,

will make an angle of $+45^{\circ}$ with this axis. The calculation results are represented in Figure 6.

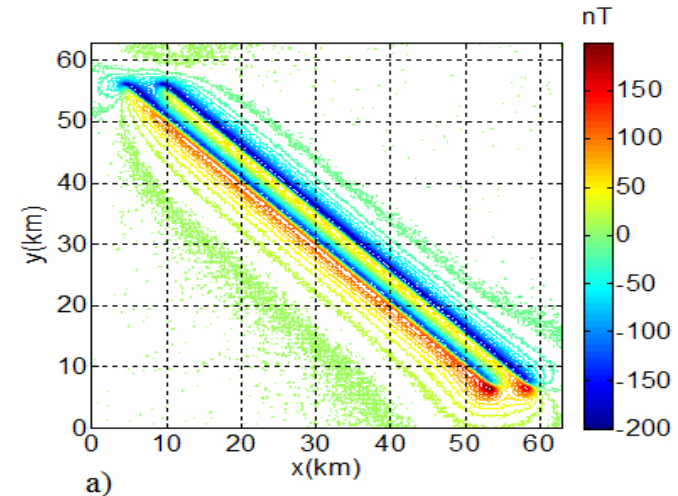

a)

Figure 5. Anomalies with noise of $1 \%$ of two parallel magnetized prisms: a) Magnetic inclination $\mathrm{I}=25^{\circ}$; b) Reduced to the pole
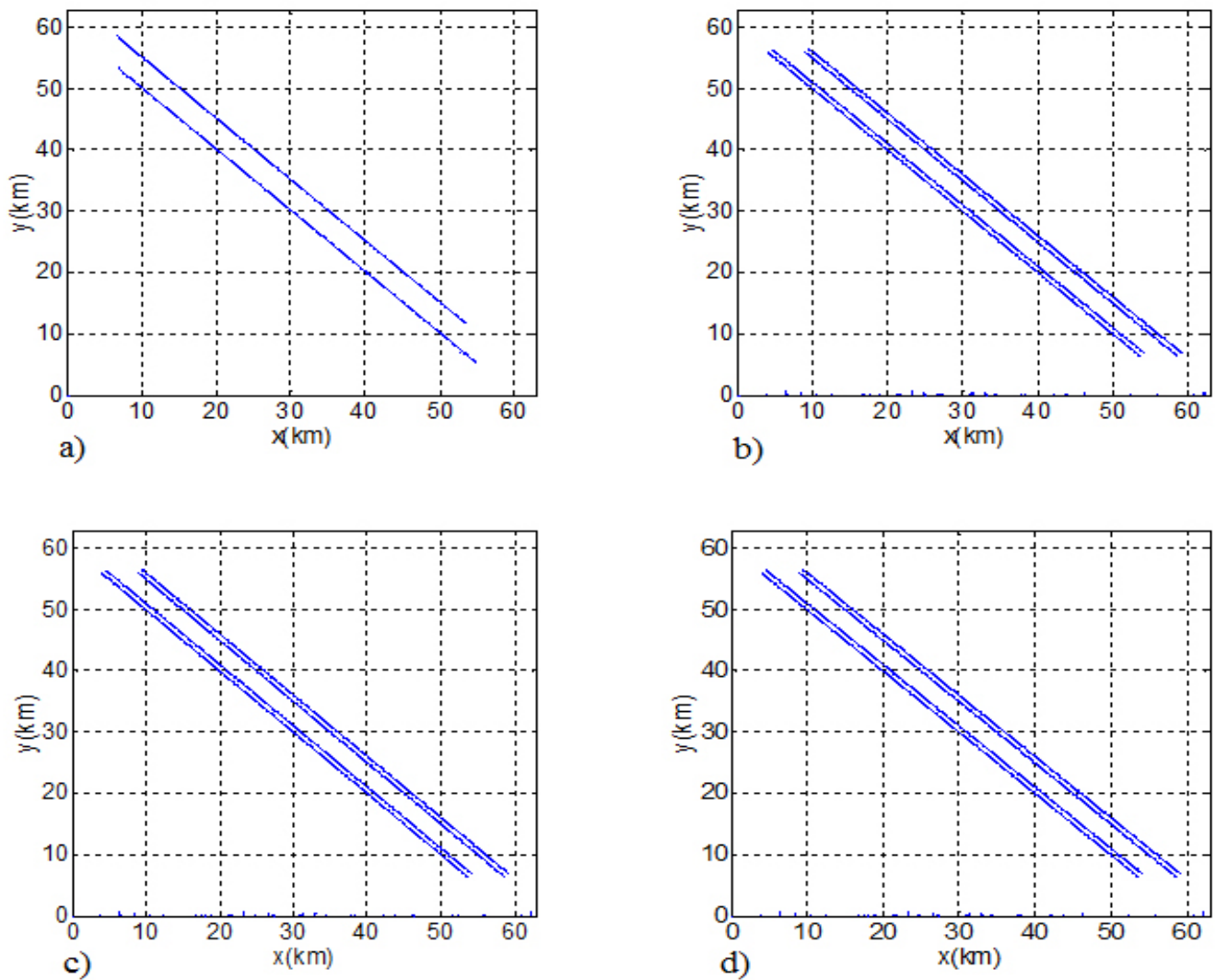

Figure 6. Determination of the boundary of two parallel magnetized prisms: a) Boundaries of object determined by $|\mathrm{HG}|_{\max }$ in case the anomalies are not reduced to the pole; b) Boundaries of object determined by $|\mathrm{HG}|_{\max }$ in case the anomalies are reduced to the pole; c) Boundaries of object determined by $|\mathrm{DG}|_{\max }$ in case the anomalies are not reduced to the pole; d) Boundaries of object determined by $|\mathrm{DG}|_{\max }$ in case the anomalies are reduced to the pole 
Nguyen Thi Thu Hang, et al./Vietnam Journal of Earth Sciences 39 (2017)

Remarks: Based on the calculation results of this model, the following remarks can be made:

In case there are many magnetic anomaly sources in the study area, with the method of using the maximum values of DG function, the extending edges of the objects are fully and clearly determined. Meanwhile, with the method of using the maximum values of $\mathrm{HG}$ function, if the anomalies are not reduced to the pole, the boundaries of two objects will not be completely represented.

\subsubsection{Model of two crossed magnetized prisms}

This model is established to investigate the interference when using the $|\mathrm{DG}|$ function to determine the boundaries of the sources in case they are very close, even cross each other. In this case, they are two vertical prisms magnetized under an inclination of $25^{\circ}$, their structural directions make the angles of $40^{\circ}$ and $60^{\circ}$ with the magnetic north, respectively. The parameters regarding coordinates, geometric dimensions and magnetization of the prisms are presented in Table 3 .

Table 3. Parameters of two crossed magnetized prisms

\begin{tabular}{ccccccccc}
\hline Parameters & $\begin{array}{c}\text { Center } \\
\text { coordinate } \\
(\mathrm{km})\end{array}$ & $\begin{array}{c}\text { Magnetic } \\
\text { declination } \\
(\mathrm{o})\end{array}$ & $\begin{array}{c}\text { Magnetization } \\
(\mathrm{A} / \mathrm{m})\end{array}$ & $\begin{array}{c}\text { Edge } \\
\text { length } \\
(\mathrm{km})\end{array}$ & $\begin{array}{c}\text { Edge } \\
\text { width } \\
(\mathrm{km})\end{array}$ & $\begin{array}{c}\text { Depth } \\
\text { to the } \\
\text { top } \\
(\mathrm{km})\end{array}$ & $\begin{array}{c}\text { Depth } \\
\text { to the } \\
\text { bottom } \\
(\mathrm{km})\end{array}$ & $\begin{array}{c}\text { Magnetic } \\
\text { inclination } \\
(\mathrm{o})\end{array}$ \\
\hline Prism1 & $31.5 ; 31.5$ & 0 & 4 & 70 & 0.3 & 0.5 & 5.0 & 25 \\
Prism2 & $31.5 ; 31.5$ & 0 & 4 & 70 & 0.3 & 0.5 & 5.0 & 25 \\
\hline
\end{tabular}

Both the not-reduced-to-the-pole anomalies $\left(\mathrm{I}=25^{\circ}\right)$ and the reduced-to-the-pole ones $\left(\mathrm{I}=90^{\circ}\right)$ are represented in Figure $7 \mathrm{a}, \mathrm{b}$ respec-

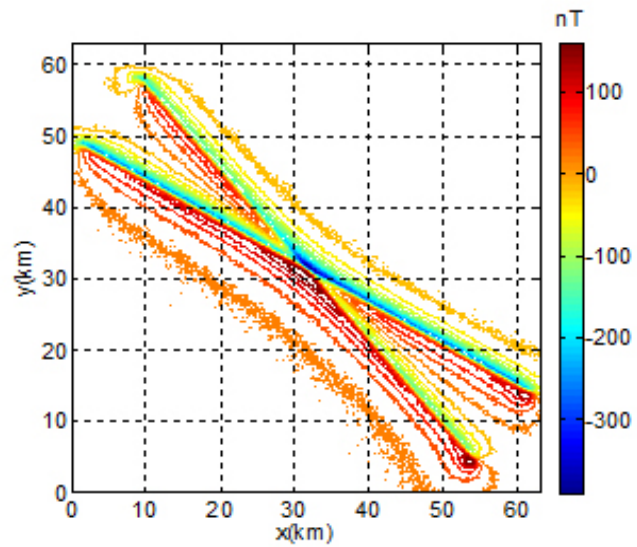

tively. In this case, the selected gradient direction makes an angle of $50^{\circ}$ with the north. The calculation results are represented in Figure 8.

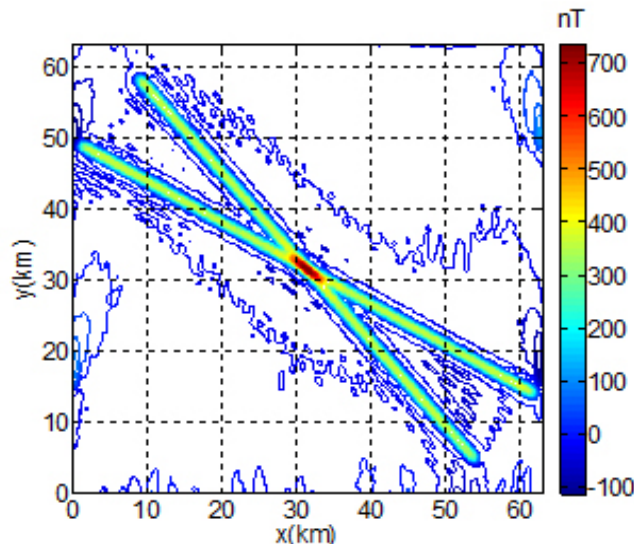

Figure 7. Anomalies with noise of $1 \%$ of two crossed magnetized prisms: a) Magnetic inclination $\mathrm{I}=25^{\circ}$; b) Reduced to the pole

Remarks: With the method of using the maximum values of DG function, the extending edges of the objects are completely and clearly determined, even in case the two objects are close together or cross each other. It indicates that this method is not affected by in- terference. This method is also slightly affected by noise. The experimental results on the model show that even when the random noise mixed in anomalies has the maximum value of $\pm 14 \mathrm{nT}\left( \pm 1 \% \Delta \mathrm{T}_{\max }\right)$, the boundary of the source is still determined with high sharpness. 
Vietnam Journal of Earth Sciences, 39(4), 360-375
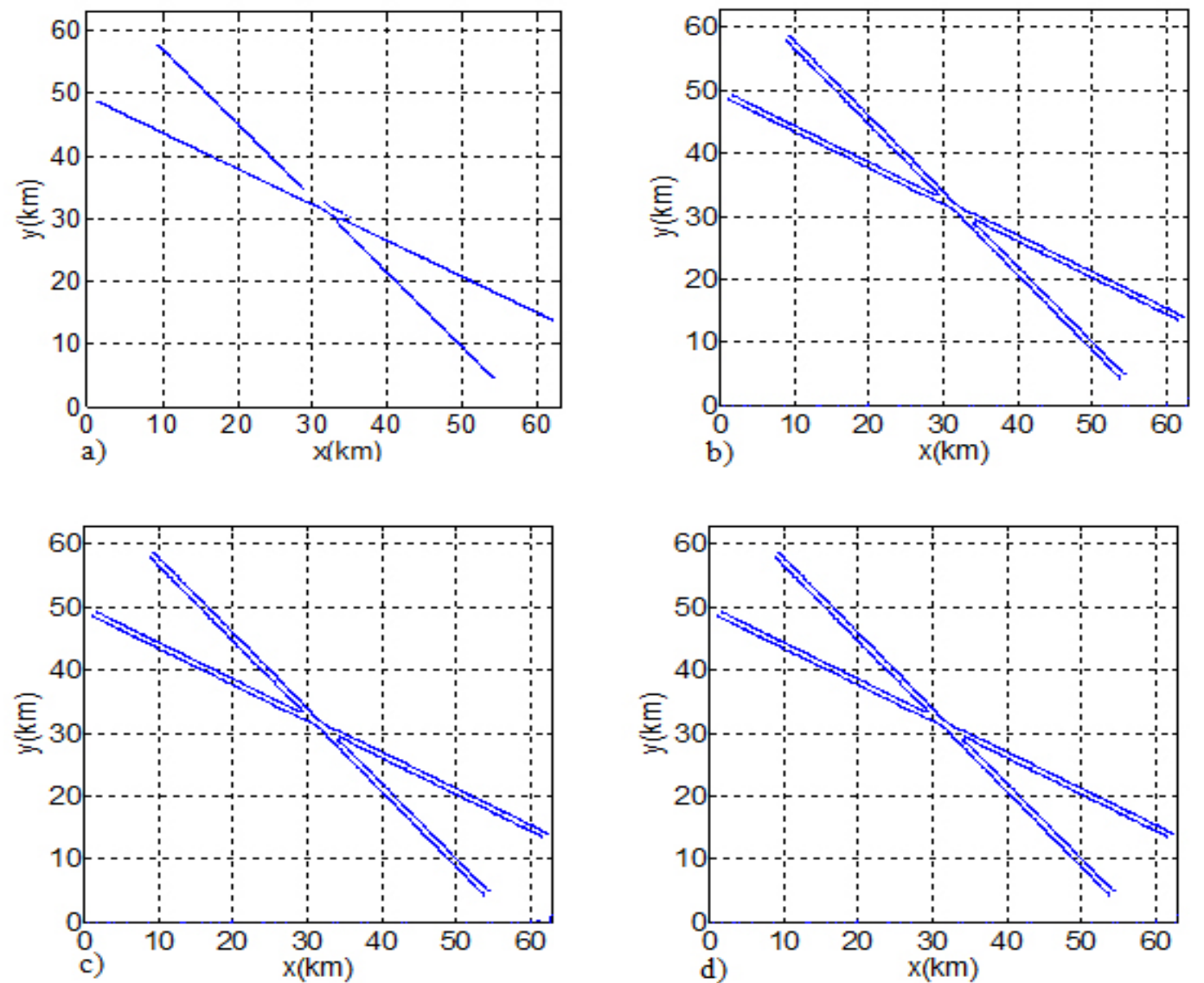

Figure 8. Determination of the boundary of two crossed magnetized prisms: a) Boundaries of object determined by $|\mathrm{HG}|_{\max }$ in case the anomalies are not reduced to the pole; $\left.b\right)$ Boundaries of object determined by $|\mathrm{HG}|_{\max }$ in case the anomalies are reduced to the pole; c) Boundaries of object determined by $|\mathrm{DG}|_{\max }$ in case the anomalies are not reduced to the pole; d) Boundaries of object determined by $|D G|_{\max }$ in case the anomalies are reduced to the pole

\subsection{Calculation results based on actual data}

From the results obtained on the numerical models, it is possible to see the distinct advantages of the method of the directional gradient (DG) in determining the boundary of anomaly source with the structure extending in one direction. In order to confirm the applicability of this method in interpreting magnetic anomaly data obtained in reality, it has been applied to interpret the aeromagnetic data in Tuan Giao area. The aeromagnetic data used in this area is the aeromagnetic anomaly map on a scale of 1:1,000,000 that was established and published in 2005 by the General Department of Geology and Minerals, bounded by longitude $\left(103^{\circ} \mathrm{E}-104^{\circ} \mathrm{E}\right)$ and latitude $\left(21^{\circ} \mathrm{N}-\right.$ $22.3^{\circ} \mathrm{N}$ ) according to geographic coordinate system (Figure 9). Le Huy Minh et al. (2001) used the method of horizontal gradient vector field $(\mathrm{HG})$ in combination with the reduction to the pole to interpret this data with the aim of determining magnetic boundaries of this area. The values of magnetic anomalies in the area vary from $-350 \mathrm{nT}$ to $50 \mathrm{nT}$, which are mainly concentrated in the northeast of the area and distributed in the northwest-southeast direction. According to the geological data, this area has the complex geological structure and strongest seismic activity in the territory of Vietnam. In the area, the major faults are the Dien Bien Lai Chau fault in the sub-longitudinal direction; the Son La fault, the Da River fault, the 
Nguyen Thi Thu Hang, et al./Vietnam Journal of Earth Sciences 39 (2017)

Ma River fault, and other northwest-southeast faults which are separated by the northeast-

southwest small faults (Cao Dinh Trieu, Pham Huy Long, 2002).

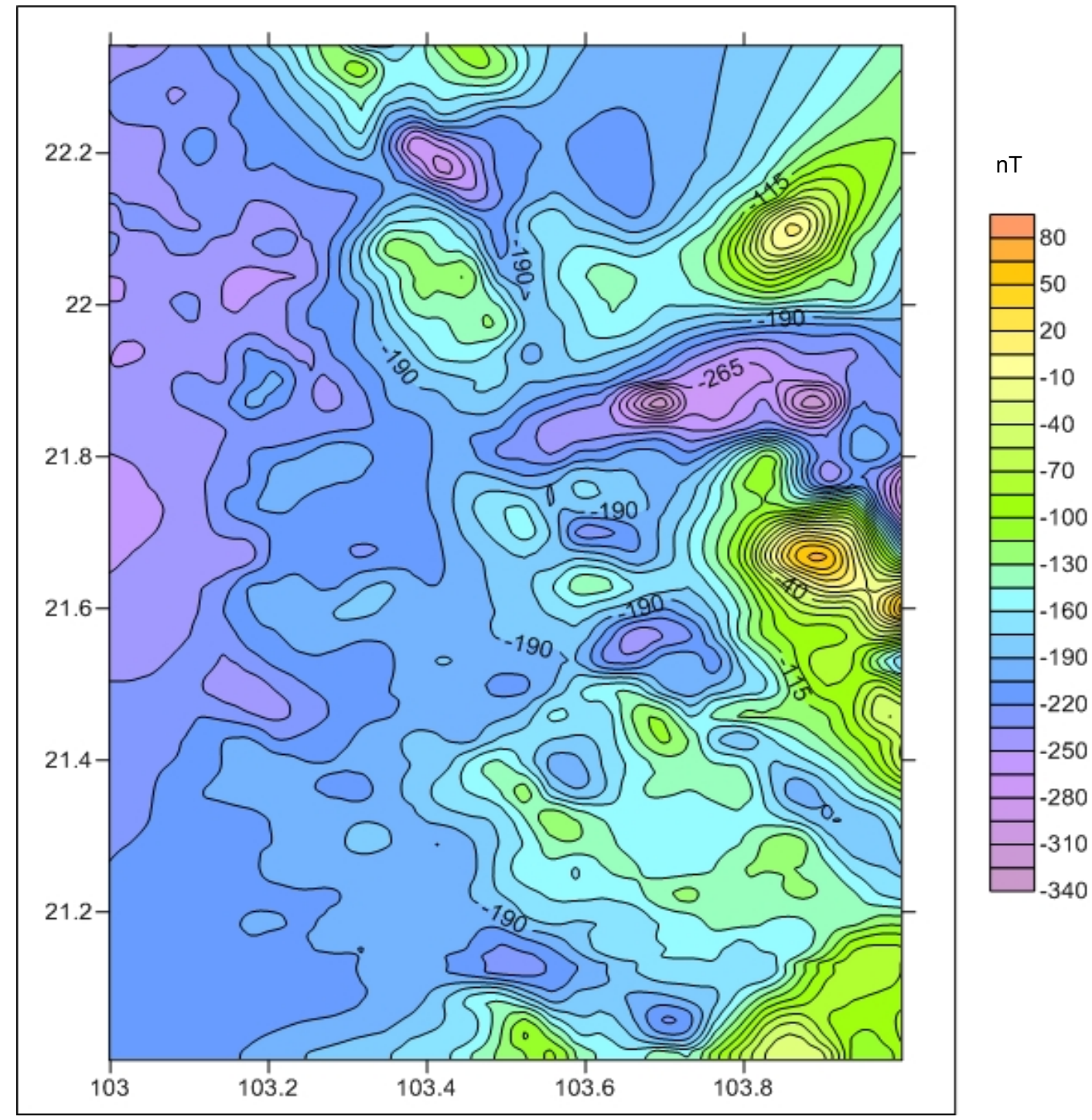

Figure 9. Aeromagnetic anomaly map $\Delta \mathrm{T}_{\mathrm{a}}$ in Tuan Giao area;

Scale 1:1,000,000 (General Department of Geology and Minerals, 2005)

The study area also consists of many geological complexes (Geological and Mineral Resources Map of Vietnam 1:200,000, the sheets Mong Kha-Son La, Phong Sa Ly-Dien Bien Phu, Kim Binh-Lao Cai, 2005) such as Ma River complex, Phun Sa Phin complex,
Ngoi Thia volcanic complex, Tu Le volcanic complex, Pu Sam Cap complex, etc. The lithologic composition of these complexes is very diverse. The Muong Hum complex consists of many types of high potassium calcalkaline rocks (monazite series) or subalkaline 
Vietnam Journal of Earth Sciences, 39(4), 360-375

granitic rocks. The Phun Sa Phin complex consists of shallow and sub-volcanic intrusive bodies of comagmatic granite and syenite together with rhyolitic-trachytic extrusive formations. The rocks in the $\mathrm{Pu}$ Sam Cap complex are mainly categorized into the alkaline series; a few are categorized into the monazite series. The rocks in these complexes are highly magnetic.

The determination of the structure of magnetic boundaries is carried out by calculating the derivatives in different directions, then computing the maximum values of new DG function $\left(\left|\mathrm{DG}_{\max }\right|\right)$. The positions of the maxima $\left(\left|\mathrm{DG}_{\max }\right|\right)$ of total magnetic anomalies $\Delta \mathrm{T}_{\mathrm{a}}$ is determined by the algorithm of Blakely \& Simpson presented above. In the figures showing the calculation results, the positions of $\left(\left|\mathrm{DG}_{\max }\right|\right)$ are represented by black dots and superimposed on the geological map of Tuan Giao area (Geological and Mineral Resources Map of Vietnam 1:200,000, the sheets Mong Kha - Son La, Phong Sa Ly - Dien Bien Phu, Kim Binh - Lao Cai, 2005).

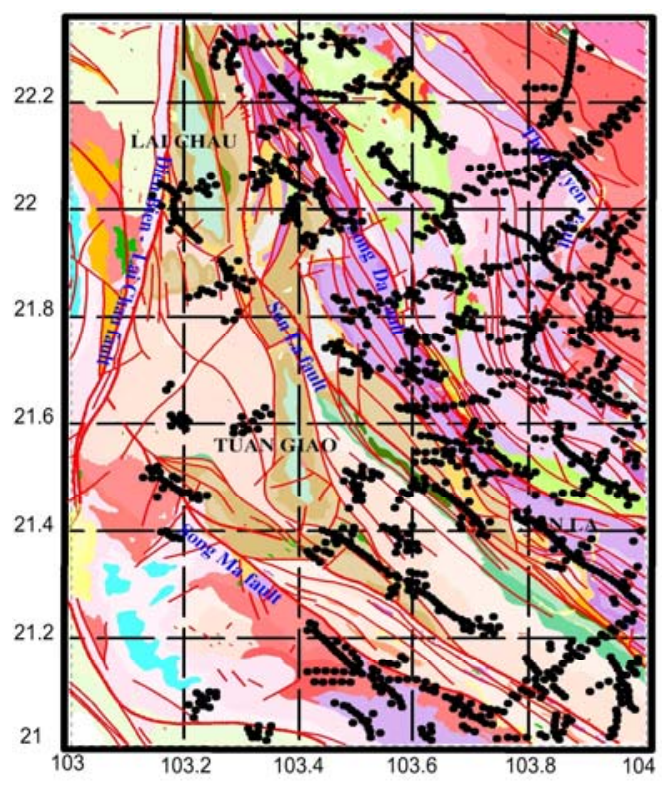

a)

\subsection{With the gradient directions being the longitudinal and northwest-southeast direc- tions}

The calculation results are represented in Figure 10a, b, respectively. The results show that with these gradient directions, the maxima of $|\mathrm{DG}|$ function $\left(|\mathrm{DG}|_{\max }\right)$ are concentrated in small clusters and distributed sparsely, unsystematically. Very few clusters are located along the faults, but they only extend to the small, short and discontinuous segments. The majority of clusters across the faults. Especially in the northwest and southwest of the study area, there are no dots representing the positions of $|\mathrm{DG}|_{\max }$, although in this area there are the Dien Bien - Lai Chau and Ma River faults whose positions are also related to magnetic boundaries (Le Huy Minh et al., 2001). It shows that in case of using the new DG function to determine boundaries of magnetic anomaly sources in Tuan Giao area, both longitudinal and northwest-southeast gradient directions are not appropriate to the geological structure of Tuan Giao area.

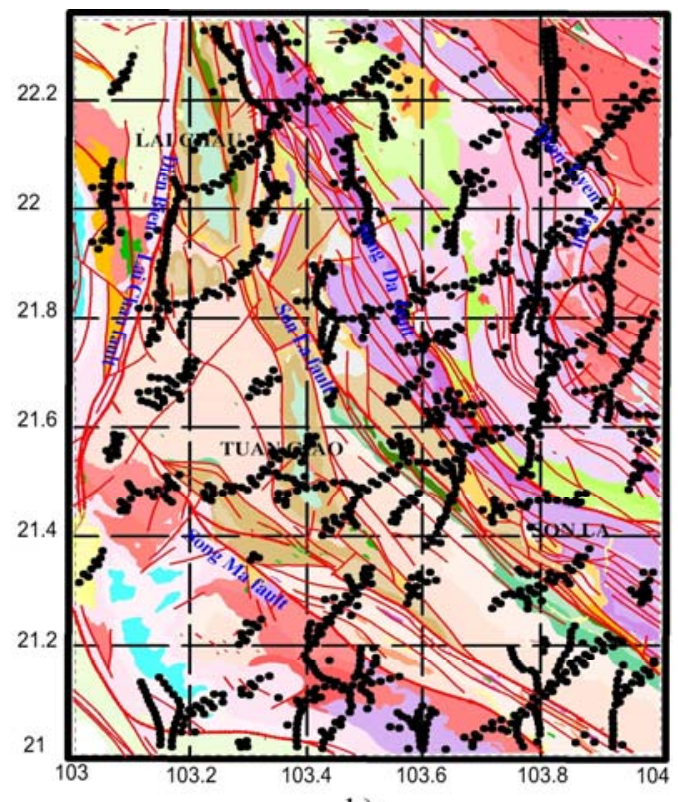

b)

Figure 10. Determination $|D G|_{\max }$ of total magnetic anomalies $\Delta \mathrm{T}_{\mathrm{a}}$ in Tuan Giao area at $\mathrm{z}=0 \mathrm{~km}$ with the gradient directions being the longtitudinal and northwest-southeast directions : a) Longtitudinal direction;

b) Northwest Southeast direction (• Positions of $|\mathrm{DG}|_{\max }$; — Faults; $\quad$ Geological complexes) 
Nguyen Thi Thu Hang, et al./Vietnam Journal of Earth Sciences 39 (2017)

\subsection{With the gradient direction being the northeast-southwest}

With this gradient direction, we have determined the positions of $|\mathrm{DG}|_{\max }$ of the total magnetic anomalies $\Delta \mathrm{T}_{\mathrm{a}}$ at $\mathrm{z}=0$ and at different levels of upward continuation in order to examine the relationship between the magnetic boundaries according to the depth of investigation.

At $z=0$ : The obtained result is represented in Figure 11. The result shows that this is the optimum gradient direction. Indeed, with this gradient direction, in the figure showing its result, the dots representing are distributed in bands and clearly follow the northwestsoutheast direction. According to the geological data, the Dien Bien - Lai Chau fault in the sub-longitudinal direction is located in the northwest of the study area; according to the result of calculating $|\mathrm{DG}|_{\max }$, the positions of $|\mathrm{DG}|_{\max }$ in this area are concentrated and spread from north to south. In the south of this fault, the position of $|\mathrm{DG}|_{\max }$ band is $5 \mathrm{~km}-10$ $\mathrm{km}$ far from the fault. In comparison with the geological map and geological features of this area, it can be seen that $|\mathrm{DG}|_{\max }$ occurs more commonly because iron ores or blocks in this area have the stronger magnetism than those in the adjacent areas. In the center of the study area, $|\mathrm{DG}|_{\max }$ occurs with high frequency and is located along the Da River fault and the majority of Son La fault in the northwestsoutheast direction. The Than Uyen fault is located in the northeast of the study area; the positions of $|\mathrm{DG}|_{\max }$ are mainly concentrated in the east of this fault, in which there are granitic blocks, tuffaceous sandstone, rhyolite, felsite of the Ngoi Thia, Tu Le and Phun Sa Phin volcanic complexes. The Ma River fault is located in the southwest and south of the study area; the positions of $|\mathrm{DG}|_{\max }$ are concentrated in the south of this fault, in which there is the Ma River formation with highly magnetic block. It is obvious that except for the magnetic boundary in the northwest following the north-south direction, in general the magnetic boundaries in the area determined by $|\mathrm{DG}|_{\max }$ follow the northwest-southeast direction, which is consistent with the main direction of geological faults in the area. Compared to the map of geological faults determined by the research results of previous authors (Geological and Mineral Resources Map of Vietnam 1:200,000, the sheets Mong Kha - Son La, Phong Sa Ly - Dien Bien Phu, Kim Binh - Lao Cai, 2005), some magnetic boundaries determined by $|\mathrm{DG}|_{\max }$ almost coincide with the positions of major faults in the area: Dien Bien Lai Chau fault in the sub-longitudinal direction, Son La fault extending from the VietnamChina border below Phong Tho through Than Uyen, Son La fault, Ma River fault, Than Uyen fault. However, some positions of the faults do not coincide completely with the positions of $|\mathrm{DG}|_{\max }$. This can be explained as follows. The dot positions (the positions of $|\mathrm{DG}|_{\max }$ ) reflect the boundaries of blocks which can be observed on the surface, but they can also reflect the deep boundaries which are not observed on the fault map.

To eliminate the effect of shallow blocks near the surface as well as to find magnetic boundaries located at different depths, the calculation of $|\mathrm{DG}|_{\max }$ has been carried out at the upward continuation to $2.5 \mathrm{~km}$ and $7.5 \mathrm{~km}$. The calculation results are represented in Figure 12, in which:

At the upward continuation to $2.5 \mathrm{~km}$ (Figure 12a): The calculation results show that at this level of upward continuation, the $|\mathrm{DG}|_{\max }$ distribution map most clearly shows the magnetic boundaries which are located deeper in the area. The separate, discrete maximum points and the small, short $|\mathrm{DG}|_{\max }$ bands reflect the small, shallow structures near the surface that have disappeared. The maximum points are clearly distributed in bands. Some structures such as the above-mentioned major extrusive masses and Son La fault, Da River fault, Ma River fault are still obviously represented. 
Vietnam Journal of Earth Sciences, 39(4), 360-375

Especially, in the southwest of the study area between longitude $103^{\circ} \mathrm{E}-103.3^{\circ} \mathrm{E}$ and latitude $21^{\circ} \mathrm{N}-21.3^{\circ} \mathrm{N}$ where the anomalies $\Delta \mathrm{T}_{a}$ are stable and the contour lines are sparse, the $|\mathrm{DG}|$ function has small value and the dots representing the positions of $|\mathrm{DG}|_{\max }$ appear infrequently. This can be because the geological complexes in this area begin from $\mathrm{Nam} \mathrm{Su}$ Lip through $\mathrm{Na}$ Khoang to Phu Sen Tung, with Suoi Bang formation, Tay Trang formation and $\mathrm{Nam} \mathrm{Su} \mathrm{Lip} \mathrm{formation,} \mathrm{which}$ consist mainly of sandstone, conglomerate, schist with weak magnetization.

At the upward continuation to $7.5 \mathrm{~km}$ (Figure 12b): At this level of upward continuation, the density of the dots representing the positions of $|\mathrm{DG}|_{\max }$ significantly reduces, but they are still distributed in bands and extend in the northwest-southeast direction. At this level, the maxima $|\mathrm{DG}|_{\max }$ only reflect the positions of magnetic boundaries which are located deeper and related to the major faults such as Da River fault, Than Uyen fault, Son La fault, Ma River fault.

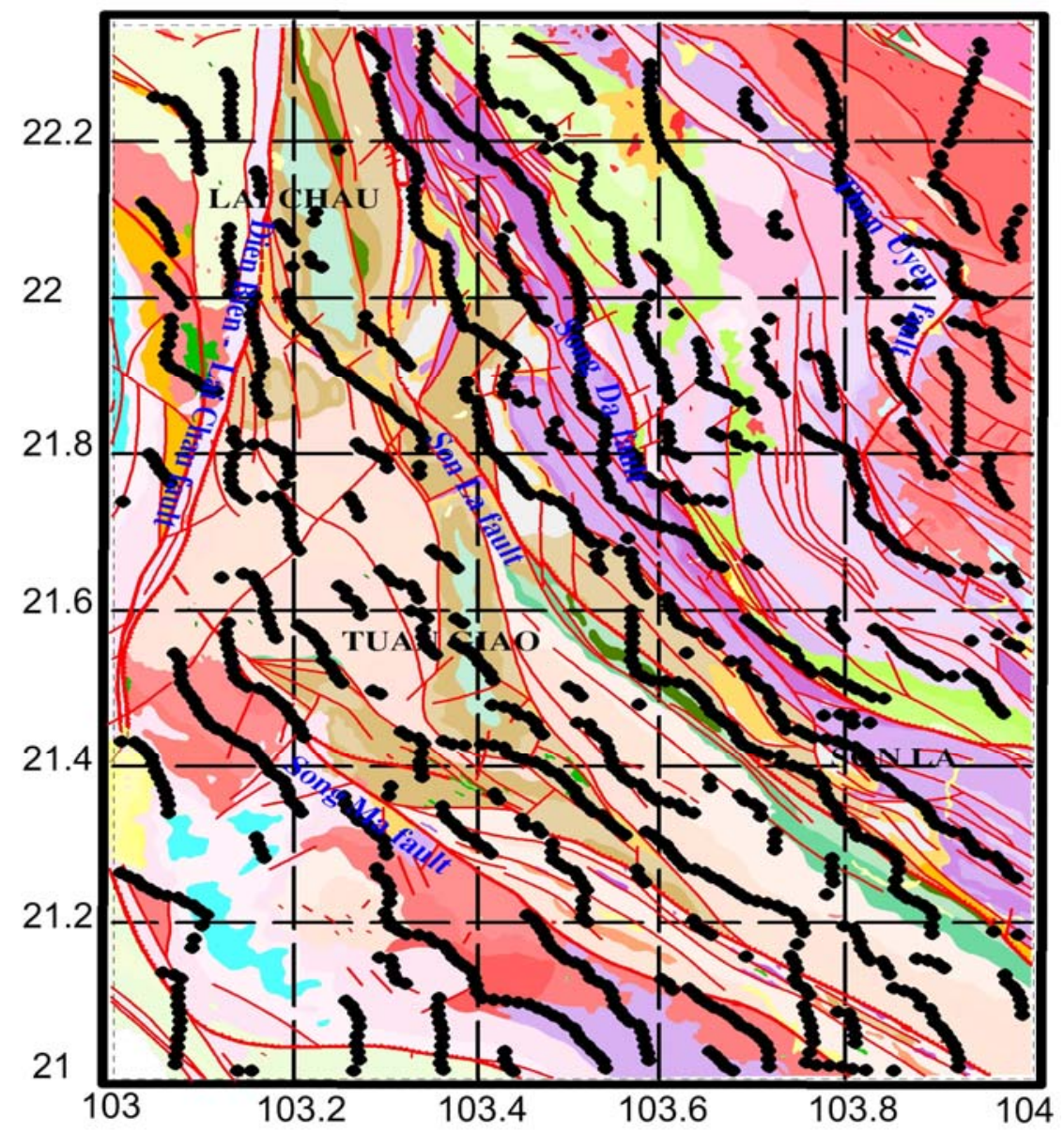

Figure 11. Determination $|\mathrm{DG}|_{\max }$ of total magnetic anomalies $\Delta \mathrm{T}_{\mathrm{a}}$ in Tuan Giao area at $\mathrm{z}=0 \mathrm{~km}$ with the gradient direction being the northeast-southwest ( Positions of $|\mathrm{DG}|_{\max } ;-$ Faults; Geological complexes) 


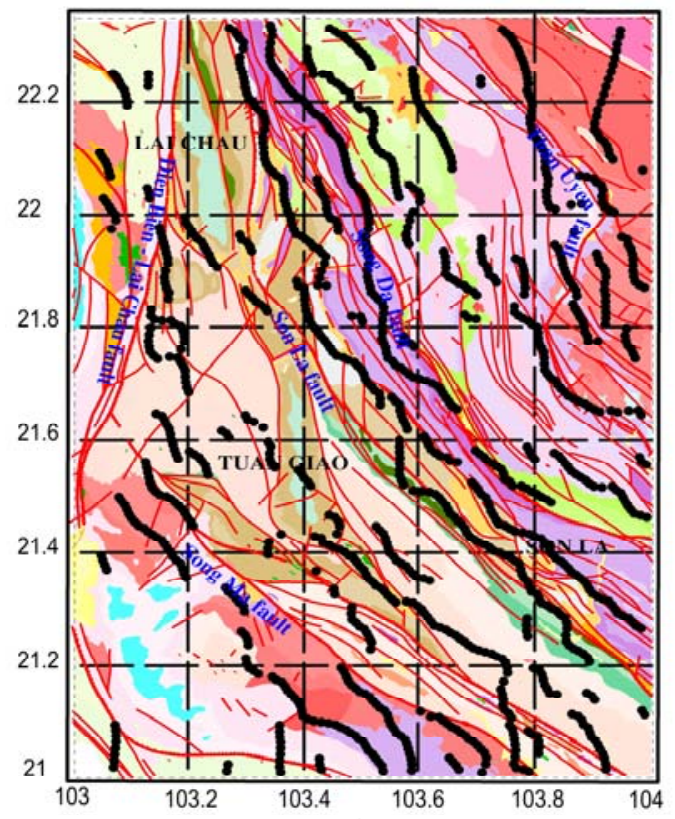

a)

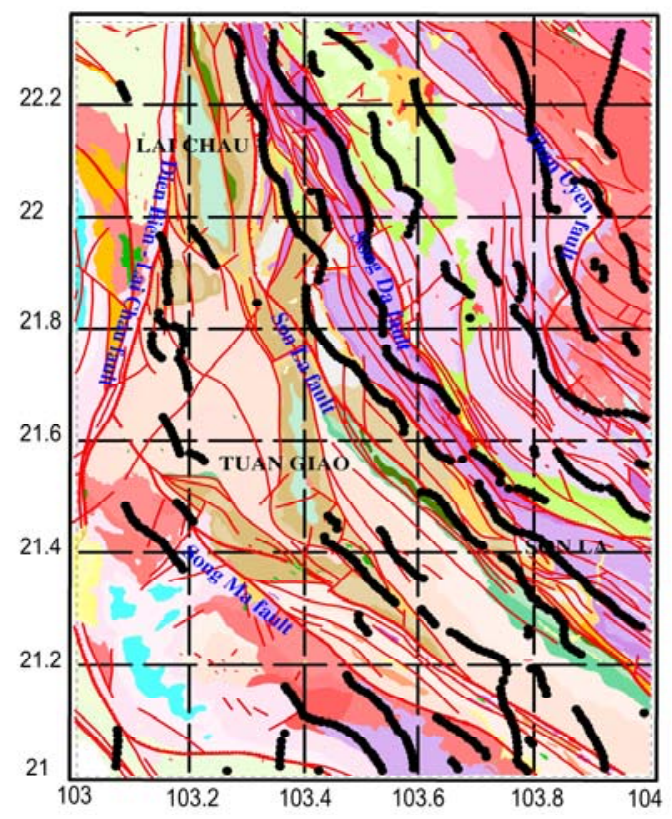

b)

Figure 12. Determination $|\mathrm{DG}|_{\max }$ of total magnetic anomalies $\Delta \mathrm{T}_{\mathrm{a}}$ in Tuan Giao area with the gradient direction being the northeast-southwest: a) at $\mathrm{z}=2,5 \mathrm{~km}$; b) at $\mathrm{z}=7,5 \mathrm{~km}$ ( $\bullet$ Positions of $|\mathrm{DG}|_{\max }$; — Faults;

Geological complexes)

\section{Discussions}

From the calculation results based on numerical models as well as actual observation data, in comparisons with the method of horizontal gradient vector field (HG) applied in the same study area, it is possible to make the following remarks on the applicability of the method of the directional gradient (DG):

With the method of using the maximum values of HG function, when the magnetized object extends in one direction and has a narrow width, if the anomalies are not reduced to the pole, the boundary of the object will not be sufficiently determined, the two boundaries in the extending direction of the object seem to be reduced to a straight line coinciding with the extending axis of the object (Figure 4a). It is only fully determined in case the anomalies are reduced to the pole before calculating HG (Figure 4b). Meanwhile, according to the maximum values of $|\mathrm{DG}|$ function ( $|\mathrm{DG}|_{\max }$ ), the determination of the boundary of the source is completely independent of the magnetization inclination of the source; even in case the anomalies are not reduced to the pole, the two boundaries in the extending direction of the source are sharply and clearly represented (Figure 4c, d).

When many sources are located in the study area or they cross each other, the method of using the maximum values of DG function still completely and sharply defines the boundaries of all objects, even if the field is not reduced to the pole. It indicates that this method is not affected by interference. The calculation results also show that this method is slightly affected by noise.

Based on the calculation with actual magnetic anomaly data in Tuan Giao area, we have found that in case of applying the directional gradient (DG) and selecting the appropriate gradient direction, although the reduc- 
Vietnam Journal of Earth Sciences, 39(4), 360-375

tion to the pole is not carried out, the calculation results show the concordance between the structural direction as well as positions of magnetic boundaries in the area determined by $|\mathrm{DG}| \max$ and the results of magnetic data analysis when using maximum horizontal gradient vector field (HG) of magnetic anomalies in Tuan Giao area after reduction to the pole and upward continuation to $2.5 \mathrm{~km}$ (Le Huy Minh, Luu Viet Hung, Cao Dinh Trieu, 2001). Moreover, according to this method (DG), the positions of magnetic boundaries extend continuously and are represented more clearly than in the HG method. This further confirms the reliability of directional gradient of total magnetic anomalies in the analysis of actual data.

\section{Conclusions}

By studying and applying the directional gradient of magnetic anomaly field to determine the boundaries of magnetized objects based on numerical models as well as actual magnetic anomaly data in Tuan Giao area, it is possible to make the following remarks:

In case the magnetic anomaly sources are narrow in width and their structure extends in one direction, the boundaries of the sources can be completely determined by the method of the directional gradient. With this method, according to the maximum values of DG function $(|\mathrm{DG}| \max )$, the determination of the boundaries of the sources does not depend on the magnetization inclination of the sources. In cases of vertical magnetization and inclined magnetization, the boundaries of the sources are sharply and clearly represented. Meanwhile, when using the method of horizontal gradient vector field, the boundaries of the sources are only represented completely in combination with the reduction to the pole. However, this intermediate step will result in significant errors in the processing, especially in case the study area is located in a lowlatitude region.
In addition, with this method, the interference which occurs in complex conditions with insignificant differentiation is also eliminated. The positions and shapes of magnetized objects are still precisely determined, even if they cross each other or the noise appears. The experimental results on the models show that even when the random noise mixed in anomalies has the maximum value of $\pm 14 \mathrm{nT}$ $\left( \pm 1 \% \Delta \mathrm{T}_{\max }\right)$, the boundaries of the sources are still determined with high sharpness.

The application of directional gradient in the analysis of aeromagnetic anomaly field in Tuan Giao area shows that the magnetic boundaries in the area basically follow the northwest-southeast direction, which is consistent with the main direction of geological faults in the area. The positions of some magnetic boundaries almost coincide with those of major faults in the area (Da River fault, Son La fault, Than Uyen fault). This indicates a connection between these geological faults and the magnetic susceptibility of associated formations.

The calculation results based on the models as well as the actual data demonstrate the applicability of directional gradient in interpreting magnetic anomaly data in Vietnam. It is particularly effective in interpreting magnetic anomaly data in the areas where the magnetic boundaries extend in one direction.

\section{References}

Bhaskara Rao D. and N. Ramesh Babu, 1993. A fortran 77 computer program for tree dimensional inversion of magnetic anomalies resulting from multiple prismatic bodies, Computer \& Geosciences, 19(8), 781-801.

Beiki M., David A. Clark, James R. Austin, and Clive A. Foss, 2012. Estimating source location using normalized magnetic source strength calculated from magnetic gradient tensor data. Geophysics, 77(6), J23-J37.

Blakely R.J., and R. W. Simpson, 1986. Approximating edges of source bodies from magnetic or gravity anomalies: Geophysics, 51, $1494-1498$.

Blakely R.J., 1995. Potential theory in gravity and magnetic applications, Cambridge University Press. 
Nguyen Thi Thu Hang, et al./Vietnam Journal of Earth Sciences 39 (2017)

Cao Dinh Trieu, Pham Huy Long, 2002. Tectonic fault in Vietnam. Publisher of Science and Engineering.

Debeglia N. and J. Corpel, 1997. Automatic 3-D interpretation of potential field data using analytic signal derivatives. Geophysics, 62, 87-96.

Geological and Mineral resources map on 1:200,000. Seriesof Tay Bac, sheets of Muong Kha - Son La (F48-XXV-F-48-XXVI), Phong Sa Ly - Dien Bien Phu (F-48-XIX-F-48-XX), Kim Binh - Lao Cai (F48-VIII-F-48-XIV), 2005. Published and copyringt by Department of Geology and Minerals of Vietnam, Hanoi.

Le Huy Minh, Luu Viet Hung, Cao Dinh Trieu, 2001. Some modern methods of the interpretation aeromagnetic data applied for Tuan Giao region. Vietnam Journal of Earth Sciences, 22(3), 207-216.

Le Huy Minh, Luu Viet Hung, Cao Dinh Trieu, 2002. Using the maximum horizontal gradient vector to interpret magnetic and gravity data in Vietnam. Vietnam Journal of Earth Sciences, 24(1), 67-80.

Nabighian M.N., 1972. The analytic signal of twodimensional magnetic bodies with polygonal crosssection: Its properties and use of automated anomaly interpretation: Geophysics, 37, 507-517.
Nabighian M.N., 1974. Additional comments on the analytic signal of two-dimensionalmagnetic bodies with polygonal cross-section. Geophysics, 39, 85-92.

Roest W. R., J. Verhoef and M. Pilkington, 1992. Magnetic interpretation using the 3-D analytic signal: Geophysics, 57, 116-125.

Vo Thanh Son, Le Huy Minh, Luu Viet Hung, 2005. Three-dimensional analytic signal method and its application in interpretation of aeromagnetic anomaly maps in the Tuan Giao region. Proceedings of the 4th geophysical scientific and technical conference of Vietnam, Publisher of Science and Engineering 2005.

Vo Thanh Son, Le Huy Minh, Luu Viet Hung, 2005. Determining the horizontal position and depth of the density discontinuties in Red River Delta by using the vertical derivative and Euler deconvolution for the gravity anomaly data, Journal of Geology, Series A, 287(3-4), 39-52.

Vo Thanh Son, et al., 2007. Determining the location and depth of contrast magnetic boundaries by using 3D analytics signal method and higher derivatives. Proceeding of the 5th geophysical scientific and technical conference of Vietnam. 